Original article

\title{
Effect of Na-doping on thermoelectric and magnetic performances of textured $\mathrm{Bi}_{2} \mathrm{Sr}_{2} \mathrm{Co}_{2} \mathrm{O}_{\mathrm{y}}$ ceramics
}

\author{
G. Çetin Karakaya ${ }^{\mathrm{a}}$, B. Özçelik ${ }^{\mathrm{a}, *}$, M.A. Torres ${ }^{\mathrm{b}}$, M.A. Madre ${ }^{\mathrm{b}}$, A. Sotelo ${ }^{\mathrm{b}}$ \\ a Department of Physics, Faculty of Sciences and Letters, Çukurova University, 01330 Adana, Turkey \\ b ICMA (CSIC-Universidad de Zaragoza), C/María de Luna 3, 50018 Zaragoza, Spain
}

\section{A R T I C L E I N F O}

\section{Keywords:}

Thermoelectrics

Laser processing

Seebeck coefficient

Power factor

Figure of merit

\begin{abstract}
A B S T R A C T
$\mathrm{Bi}_{2} \mathrm{Sr}_{2-\mathrm{x}} \mathrm{Na}_{\mathrm{x}} \mathrm{Co}_{2} \mathrm{O}_{\mathrm{x}}(\mathrm{x}=0.0,0.025,0.050,0.075,0.100$, and 0.125$)$ samples were prepared through the solidstate route and textured using the laser floating zone technique. Microstructural analysis of as-grown samples showed well oriented grains and a relatively high amount of secondary phases due to their incongruent melting. Annealing procedure has drastically decreased the number and amount of secondary phases. Moreover, Nadoping has further decreased the secondary phases content and improved grain alignment. These modifications have been reflected in a large decrease of electrical resistivity with the annealing procedure. The maximum power factor values have been obtained in 0.075 Na-doped annealed samples, $0.20 \mathrm{~mW} / \mathrm{K}^{2} \mathrm{~m}$, which are much higher than the best values obtained in textured materials through hot uniaxial pressing. Magnetic properties were very similar for all samples, with paramagnetic Curie temperature and effective magnetic moment values of $-48.6 \mathrm{~K}$ and $\approx 2 \mu_{B}$, respectively.
\end{abstract}

\section{Introduction}

Thermoelectric (TE) materials are characterized by their ability to transform a temperature gradient to electricity without any moving part. As a consequence, they can increase the efficiency of classical energy transforming systems when they are used to recover the wasted heat $[1,2]$. Moreover, they can be applied as thermoelectric generators $[2,3]$ or heating/cooling devices $[2,4,5]$. The efficiency of these materials is quantified using the expression $\mathrm{TS}^{2} / \rho \mathrm{k}$ (dimensionless figure of merit, ZT), where T, S, $\rho$, and $\kappa$ are absolute temperature, Seebeck coefficient, electrical resistivity, and thermal conductivity, respectively [6].

At present, many commercial thermoelectric systems are built using metallic alloys or intermetallic legs, such as $\mathrm{Bi}_{2} \mathrm{Te}_{3}$ or $\mathrm{PbTe}$ which possess high performances at relatively low temperatures [7-9]. Consequently, the high-temperature wasted heat cannot be harvested using these systems. Moreover, they can be degraded and/or release toxic or heavy elements when working in these conditions under air. The possibility to use materials working at high temperatures was reported in 1997, when discovering attractive thermoelectric properties in $\mathrm{NaCo}_{2} \mathrm{O}_{4}$ ceramics [10]. This finding boosted the research on different CoO-based thermoelectric ceramics, as $\mathrm{Ca}_{3} \mathrm{Co}_{4} \mathrm{O}_{9}$ (349), $\mathrm{LaCoO}_{3}$, or $\mathrm{Bi}_{2} \mathrm{AE}_{2} \mathrm{Co}_{2} \mathrm{O}_{\mathrm{x}}$ ( $\mathrm{AE}=$ Alkaline earth) [11-15], with p-type behavior. On the other hand, the study of transition metal oxide systems led to other compounds, as TiO- and MnO-based materials [16,17], which showed $\mathrm{n}$-type behavior and can be used as the p-type counterpart in the thermoelectric modules.

The crystalline structure of these $\mathrm{CoO}$ families can be described as a monoclinic structure formed, in turn, by an alternate stacking of two layers: a conductive $\mathrm{CoO}_{2}$ layer with $\mathrm{CdI}_{2}$-structure and a rock-salt-type block one. These two layers possess common $a$ - and $c$-axis lattice parameters and $\beta$ angles but different $b$-axis length, leading to a misfit structure along the $b$-direction $[18,19]$. Consequently, the grains possess a large crystallographic anisotropy, reflected in the anisotropy of their electrical properties. As it is well known, the misfit factor and the charge in the rock-salt layer, influence the Seebeck coefficient values [20]. These characteristics have to be considered when tuning up their thermoelectric properties. Following these considerations, many routes have been tested to improve thermoelectric performances, as doping processes [21-25], or texturing techniques [26-30].

The aim of the present work is determining the effect of $\mathrm{Na}$ aliovalent substitution for $\mathrm{Sr}$ on the microstructure, and thermoelectric performances of laser floating zone (LFZ) textured $\mathrm{Bi}_{2} \mathrm{Sr}_{2} \mathrm{Co}_{2} \mathrm{O}_{\mathrm{x}}$ materials.

\section{Experimental}

Polycrystalline $\mathrm{Bi}_{2} \mathrm{Sr}_{2-\mathrm{x}} \mathrm{Na}_{\mathrm{x}} \mathrm{Co}_{2} \mathrm{O}_{\mathrm{x}}(\mathrm{x}=0,0.025,0.05,0.075,0.10$,

\footnotetext{
* Corresponding author.

E-mail address: ozcelik@cu.edu.tr (B. Özçelik).
} 
and 0.125$)$ ceramic precursors have been prepared through the classical solid state method, using $\mathrm{Bi}_{2} \mathrm{O}_{3}$ (99\%, Panreac), $\mathrm{SrCO}_{3}$ (99\%, Panreac), $\mathrm{Na}_{2} \mathrm{CO}_{3}$ (99\%, Panreac), and $\mathrm{CoO}$ (99.99\%, Aldrich) commercial powders as starting materials. They were weighed in the appropriate proportions, mixed, and ball milled for $30 \mathrm{~min}$ at $300 \mathrm{rpm}$ in water media. The suspension was totally dried under infrared radiation and the powder was manually milled to break the agglomerates. The homogeneous mixture has been heated twice, at 750 and $800{ }^{\circ} \mathrm{C}$, for about $12 \mathrm{~h}$ under air, with an intermediate manual milling, to decompose $\mathrm{Na}$, and $\mathrm{Sr}$ carbonates. This process is necessary to avoid their decomposition during the texturing process, otherwise they would produce $\mathrm{CO}_{2}$ bubbles inside the melt, leading to the crystallization front destabilization [31]. After the thermal treatments, the powders were cold isostatically pressed at $\sim 200 \mathrm{MPa}$ to obtain green ceramic cylinders $(\phi=2-3 \mathrm{~mm}$ and $100 \mathrm{~mm}$ length). These cylindrical precursors were subsequently used as feed in a LFZ device equipped with a continuous power Nd:YAG laser $(\lambda=1064 \mathrm{~nm})$ [32]. All samples have been directionally grown at $30 \mathrm{~mm} / \mathrm{h}$, and subjected to $3 \mathrm{rpm}$ seed rotation to maintain the cylindrical geometry. Moreover, an opposite feed rotation of $15 \mathrm{rpm}$ has been used to improve the cations distribution in the molten zone. After the texturing process, geometrically homogeneous textured cylindrical rods $(\sim 2 \mathrm{~mm}$ diameter) have been obtained. As it has been previously reported, these materials melt incongruently and are composed by a large number of secondary phases [33]. Therefore, some of the as-grown samples were annealed at $810{ }^{\circ} \mathrm{C}$ for $24 \mathrm{~h}$ with a final furnace cooling to maximize the thermoelectric phase content.

Phases identification was performed through powder X-ray diffraction (XRD) analysis using a Rigaku D/max-B X-ray powder diffractometer (CuKa radiation), between 10 and $60^{\circ}$. Microstructural evolution has been studied on polished longitudinal sections of asgrown and annealed samples in a field emission scanning electron microscope (FESEM, Zeiss Merlin). Qualitative chemical composition has been determined through energy dispersive X-ray spectroscopy (EDS). Moreover, density of samples has been quantified using Archimedes method, and $6.8 \mathrm{~g} / \mathrm{cm}^{3}$ as theoretical density [34].

Electrical resistivity and Seebeck coefficient were determined by the standard dc four-probe technique in a LSR-3 measurement system (Linseis $\mathrm{GmbH}$ ) between 50 and $650{ }^{\circ} \mathrm{C}$. With these data, power factor $\left(\mathrm{PF}=\mathrm{S}^{2} / \rho\right)$ has been calculated to determine the samples performances. The magnetic properties were measured in a physical property measurement system PPMS system (Dyne-cool PPMS, Quantum Design) magnetometer. The magnetic hysteresis data have been obtained between -4 and $4 \mathrm{~T}$ external applied fields, and magnetization measurements have been made under 20 Oe dc external field between $5 \mathrm{~K}$ and room temperature, in zero field cooled (ZFC) mode.

\section{Results and discussion}

Powder XRD patterns (from 10 to $40^{\circ}$, for clarity) of representative as-grown and annealed samples are displayed in Fig. 1. In the graph, the diffraction planes indicate the peaks associated to the thermoelectric phase, in agreement with previously published data [35]. Moreover, as it can be clearly observed in Fig. 1a, and b, as-grown samples possess several secondary phases, identified using the peaks marked with *,+ and \# in Fig. 1a $\left(\mathrm{Bi}_{0.75} \mathrm{Sr}_{0.25} \mathrm{O}_{\mathrm{y}}\right.$ [36], Sr-rich Bi-Sr-Co-O [37], and Co oxide [38], respectively). When comparing these two patterns, it is easy to deduce that Na-doping decreases the amount of secondary phases, when compared with the undoped ones. On the other hand, when observing Fig. 1c-e, it is clear that annealing procedure drastically reduces the amount of secondary phases (from the as-grown ones), leading to nearly single phase materials. Another important feature observed in these patterns is that the most intense peaks correspond to the ab planes. This effect is associated to the grains shape (thin and large plate-like grains) [38], which tend to be preferentially oriented with their ab planes parallel to the sample holder surface during the

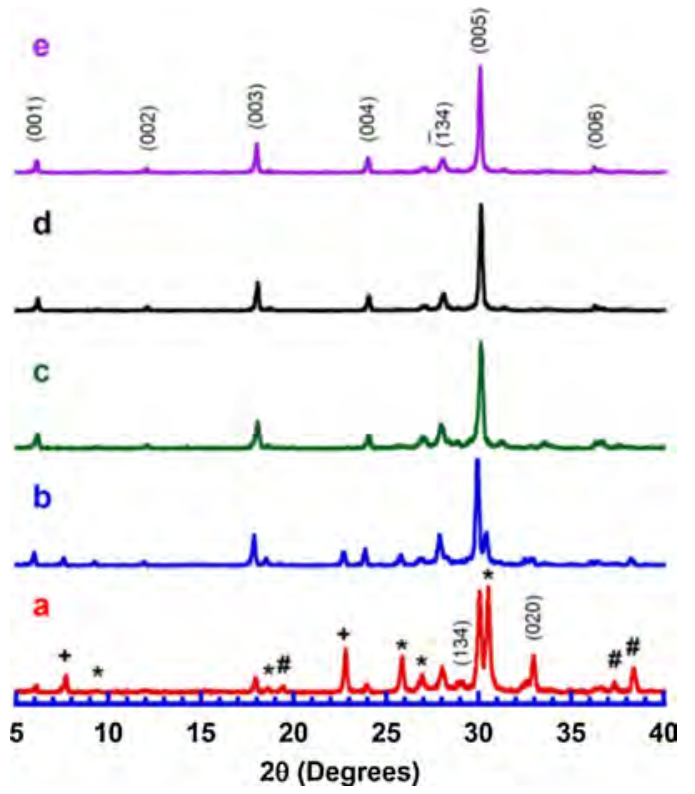

Fig. 1. XRD patterns of representative $\mathrm{Bi}_{2} \mathrm{Sr}_{2-\mathrm{x}} \mathrm{Na}_{\mathrm{x}} \mathrm{Co}_{2} \mathrm{O}_{\mathrm{y}}$ as-grown samples with $\mathrm{x}$ : a) 0; and b) 0.075; and annealed ones with $\mathrm{x}$ : c) 0; d) 0.075; and e) 0.1. Crystallographic planes indicate the peaks corresponding to the thermoelectric phase. *, \#, and + correspond to $\mathrm{Bi}_{0.75} \mathrm{Sr}_{0.25} \mathrm{O}_{\mathrm{y}}, \mathrm{CoCo}_{2} \mathrm{O}_{4}$, and $\mathrm{Bi}_{3.8} \mathrm{Sr}_{11.4} \mathrm{Co}_{8} \mathrm{O}_{28.875}$ secondary phases, respectively.

samples preparation.

Representative FESEM micrographs of longitudinal polished surfaces of as-grown (a, and b) and annealed (c, and d) samples are shown in Fig. 2. The micrographs show several contrasts, indicated by numbers, which correspond to different chemical compositions. These contrasts have been associated, through EDS, to: 1) thermoelectric phase; 2) Co-poor Bi-Sr-Co-O; 3) Bi-Sr-O; 4) Bi-poor Bi-Sr-Co-O; and 5) Co oxide. When comparing undoped and 0.075 Na-doped as-grown samples (Fig. 2a, and b), it is clear that Na-doping decreases the amount of secondary phases, in agreement with the XRD data previously discussed. Moreover, Na-doping leads to a decrease of melting point of samples, reflected in a better grain alignment with respect to the growth direction, due to a lower radial gradient in the solidification front, as observed in similar systems [40]. On the other hand, the effect of annealing can be easily seen when comparing Fig. $2 \mathrm{~b}$, and c, corresponding to $0.075 \mathrm{Na}$ doped samples before and after annealing, respectively. As it can be observed in these pictures, annealing decreases the amount and number of secondary phases (\#2, and \# 4 dissapear). This microstructural evolution evidence that annealing conditions are adequate to promote the TE phase formation from the secondary ones. Moreover, when increasing Na-doping, the secondary phases content still decreases (see Fig. 2c, and d).

Another important feature observed in as-grown and annealed samples (see Fig. 2) is their very low porosity. This is a typical effect of the melt-solidification process when applied to related ceramic systems $[41,42]$. The high density of these samples has been confirmed through the Archimedes method, reaching $97 \pm 2 \%$ of the theoretical values in all cases.

The microstructural evolution is clearly reflected in the electrical resistivity displayed in Fig. 3 for as-grown and annealed samples. As it can be observed in the graph, as-grown samples show semiconductinglike behavior $(\mathrm{d} \rho / \mathrm{dT}<0)$ in the whole measured temperature range, while the annealed possess metallic-like one $(\mathrm{d} \rho / \mathrm{dT}>0)$. The difference between these two groups of samples can be associated to the larger amount of thermoelectric phase after annealing, and the oxygen content in the thermoelectric phase, which affects the charge carrier concentration. It is well known that LFZ growth promotes the formation of a high number of oxygen vacancies in the textured materials [43], decreasing the charge carrier concentration. On the other hand, 

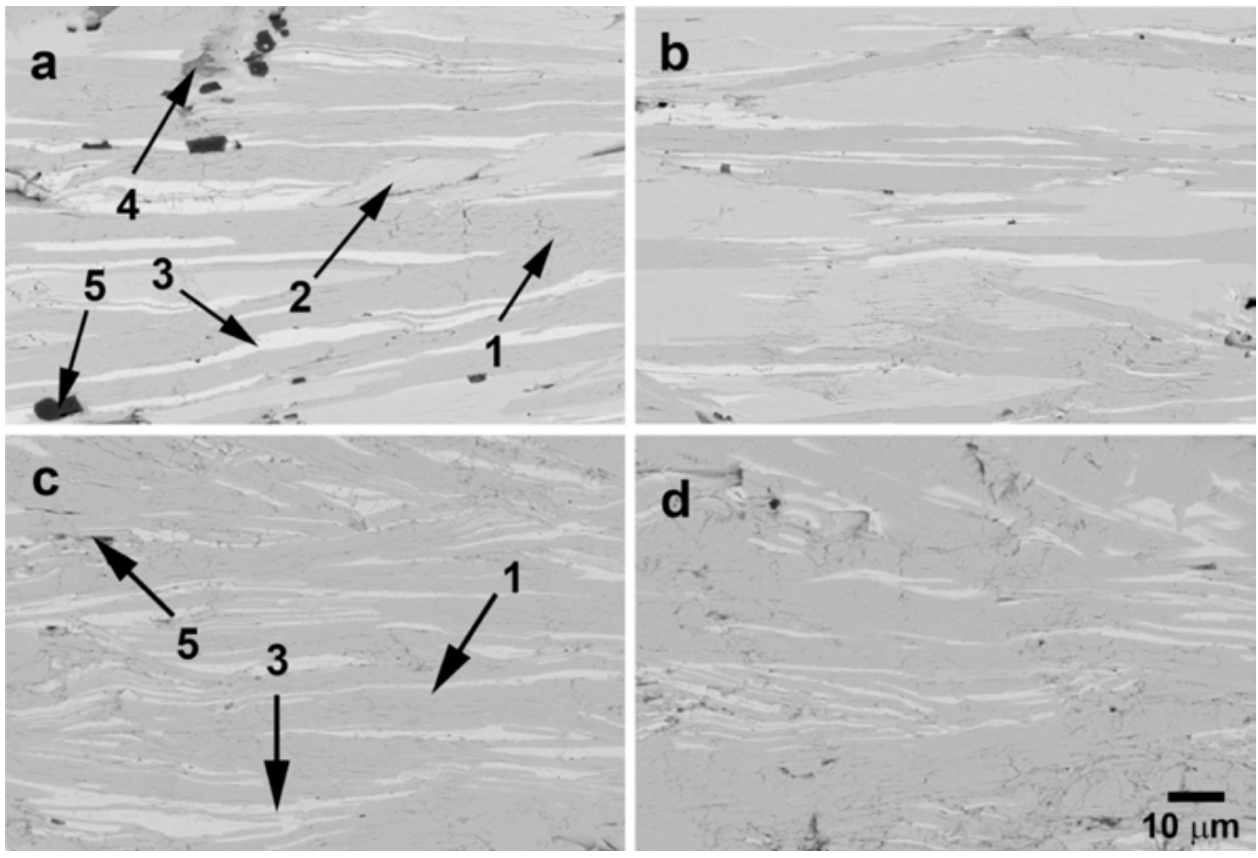

Fig. 2. Representative SEM micrographs of longitudinal polished $\mathrm{Bi}_{2} \mathrm{Sr}_{2-\mathrm{x}} \mathrm{Na}_{\mathrm{x}} \mathrm{Co}_{2} \mathrm{O}_{\mathrm{y}}$ as-grown samples with $\mathrm{x}$ : a) 0 ; and b) 0.075 , and annealed ones with $\mathrm{x}$ : c) 0.075 ; and d) 0.10 . The numbers indicate the different phases: 1) thermoelectric phase; 2) Co-poor Bi-Sr-Co-O; 3) Bi-Sr-O; 4) Bi-poor Bi-Sr-Co-O; and 5) Co oxide.

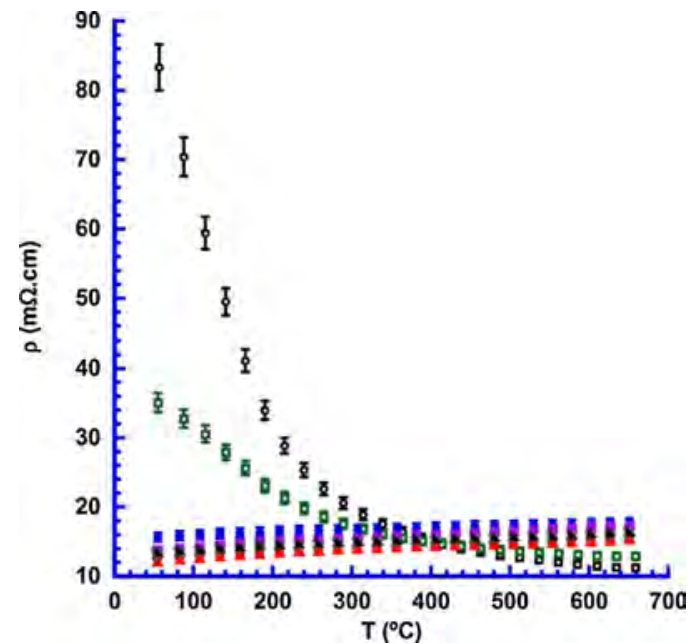

Fig. 3. Temperature dependence of electrical resistivity for $\mathrm{Bi}_{2} \mathrm{Sr}_{2-\mathrm{x}} \mathrm{Na}_{\mathrm{x}} \mathrm{Co}_{2} \mathrm{O}_{\mathrm{y}}$ as-grown samples with x: 0 ; and 0.075 ; and annealed ones with $\mathrm{x}: 0$; $0.025 ; \diamond 0.05$; $\Delta$ 0.075 ; $\nabla .10$; and 0.125 . The bars illustrate the uncertainty of the measured values.

annealing allows oxygen diffusion into the structure, decreasing the number of oxygen vacancies, raising the charge carrier concentration and decreasing electrical resistivity values. When considering Na-doped annealed samples, electrical resistivity is lowered up to $0.75 \mathrm{Na}$ content, increasing for higher substitution. In any case, they always possess lower electrical resistivity than the undoped samples. This evolution is found in as-grown and annealed samples, even if the Na-doping effect is more important in as-grown samples. This is because Na raises the amount of thermoelectric phase in the samples, decreasing the annealing effectivity. The evolution of electrical resistivity as a function of Na-content can be associated to the relationship between two opposite effects: the charge modification in the rock-salt layer, and the decrease of the charge carrier mobility. For the first effect, when $\mathrm{Na}^{+}$substitutes $\mathrm{Sr}^{2+}$, the charge in the rock-salt layer reduced and $\mathrm{Co}^{3+}$ in the conducting layer is promoted to $\mathrm{Co}^{4+}$ to maintain the total charge neutrality in the structure, increasing the charge carrier concentration. The second effect is due to the introduction of defects in the crystal structure due to the different $\mathrm{Na}^{+}$and $\mathrm{Sr}^{2+}$ sizes and atomic weight, decreasing the carriers mobility. Therefore, the electrical resistivity evolution can be explained considering that up to 0.075 Na-substitution, the increase of charge carrier concentration is the dominant effect, while for higher $\mathrm{Na}$ content, the decrease of mobility becomes more important. In any case, the lowest resistivity values at room temperature have been obtained in annealed $0.075 \mathrm{Na}$ doped samples $(12 \mathrm{~m} \Omega \mathrm{cm})$. It is worth to mention that these values possess an estimated $4 \%$ uncertainty taking into account the sensitivity of the measuring system, and the inaccuracy in the measurements of samples dimensions, and the distance between the contacts, as reported in previous works [44]. These mean values are lower than the ones obtained in samples produced by solution methods $(22 \mathrm{~m} \Omega \mathrm{cm})$ [39], sintered materials under oxygen $(15 \mathrm{~m} \Omega \mathrm{cm})$ [26], or single crystals $(18 \mathrm{~m} \Omega \mathrm{cm})$ [45]. At $650^{\circ} \mathrm{C}$, the minimum electrical resistivity values in annealed samples $(15 \mathrm{~m} \Omega \mathrm{cm}$ for 0.075 Na-doped ones) are similar to the reported in sintered materials under oxygen atmosphere $(\sim 15 \mathrm{~m} \Omega \mathrm{cm})$ [26]. Moreover, they are much lower than the ones obtained in sinter-forged materials $(\sim 40 \mathrm{~m} \Omega \mathrm{cm})$ [46].

Fig. 4 displays the Seebeck coefficient variation with temperature for as-grown and annealed samples. The sign of the Seebeck coefficient is positive in the whole measured temperature range for all the samples,

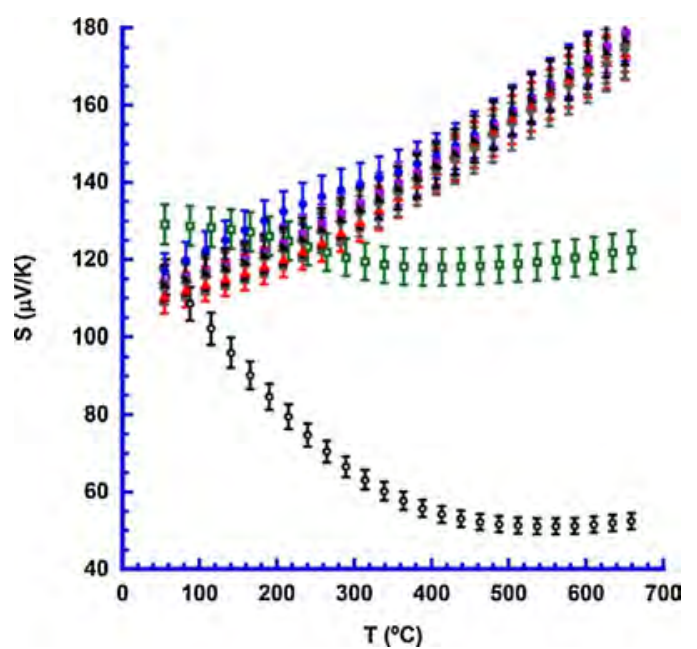

Fig. 4. Temperature dependence of Seebeck coefficient for $\mathrm{Bi}_{2} \mathrm{Sr}_{2-\mathrm{x}} \mathrm{Na}_{\mathrm{x}} \mathrm{Co}_{2} \mathrm{O}_{\mathrm{y}}$ as-grown

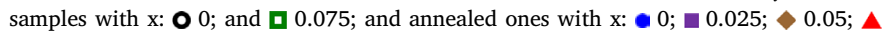
0.075 ; 0.10 ; and 0.125 . The bars illustrate the uncertainty of the measured values. 
confirming a conduction mechanism mainly governed by holes. On the other hand, the as-grown and annealed samples exhibit very different behaviour. In the as-grown samples Seebeck coefficient is decreased when the temperature is increased, while it is raised with temperature in the annealed ones. The difference between both types of samples can be also explained by the high number of oxygen vacancies produced by the LFZ process and its reduction after annealing. The increase of oxygen vacancies in the thermoelectric phase decreases the charge carrier concentration (reflected in higher room temperature $S$ values), as observed in similar systems [30]. The highest Seebeck coefficient at room temperature has been obtained in $0.075 \mathrm{Na}$-doped as-grown samples, around $10 \%$ higher than the measured in the annealed ones. An uncertainty of around 4\% has been determined in these measurements, coming from the temperature determination in the hot and cold sides of the samples [44]. In any case, the highest values determined in annealed samples at this temperature are around $115 \mu \mathrm{V} / \mathrm{K}$, which are about the obtained in sintered materials under oxygen atmosphere $(125 \mu \mathrm{V} / \mathrm{K})$ [26], single crystals $(115 \mu \mathrm{V} / \mathrm{K})$ [45], or sinter-forged materials $(110 \mu \mathrm{V} / \mathrm{K})[46]$. At $650{ }^{\circ} \mathrm{C}$, the maximum values are close to $180 \mu \mathrm{V} / \mathrm{K}$, higher than the obtained in sinter-forged materials $(\sim 150 \mu \mathrm{V} / \mathrm{K})[46]$, but lower than the measured in samples produced through solution methods $(205 \mu \mathrm{V} / \mathrm{K})$ [39].

The thermoelectric performances of these materials have been evaluated through the power factor, presented as a function of temperature, in Fig. 5. Taking into account the electrical resistivity, and Seebeck coefficient uncertainties, it is possible estimating the uncertainty of $\mathrm{PF}$ values using the principle of error propagation. Moreover, taking into account the number of measurements at each temperature, the $9 \%$ uncertainty is the upper limit. At room temperature, the highest values $\left(0.10 \mathrm{~mW} / \mathrm{K}^{2} \mathrm{~m}\right.$ in $0.075 \mathrm{Na}$-doped annealed samples) are more than twice the best determined in as-grown materials. Moreover, they are higher than the measured in single crystals $\left(0.07 \mathrm{~mW} / \mathrm{K}^{2} \mathrm{~m}\right)$ [45], and similar to the reported in sintered materials under oxygen atmosphere $\left(0.10 \mathrm{~mW} / \mathrm{K}^{2} \mathrm{~m}\right)$ [26]. Finally, at $650{ }^{\circ} \mathrm{C}$, the maximum PF $\left(0.20 \mathrm{~mW} / \mathrm{K}^{2} \mathrm{~m}\right.$ in $0.075 \mathrm{Na}$-doped annealed samples $)$, is similar to the measured in samples produced by solution methods $\left(0.20 \mathrm{~mW} / \mathrm{K}^{2} \mathrm{~m}\right)$ [39], but much higher than the ones measured in sinter-forged materials $\left(0.05 \mathrm{~mW} / \mathrm{K}^{2} \mathrm{~m}\right)$ [46].

It is well known that thermoelectric parameters, as Seebeck coefficient, are very sensitive to slight variations in the magnetic properties. Therefore, the temperature dependence of magnetization has been determined on annealed samples, and presented in Fig. 6. In the graph, it can be seen that all samples are very similar: magnetic susceptibility sharply drop between 5 and $35 \mathrm{~K}$, and then slowly decrease above $35 \mathrm{~K}$.

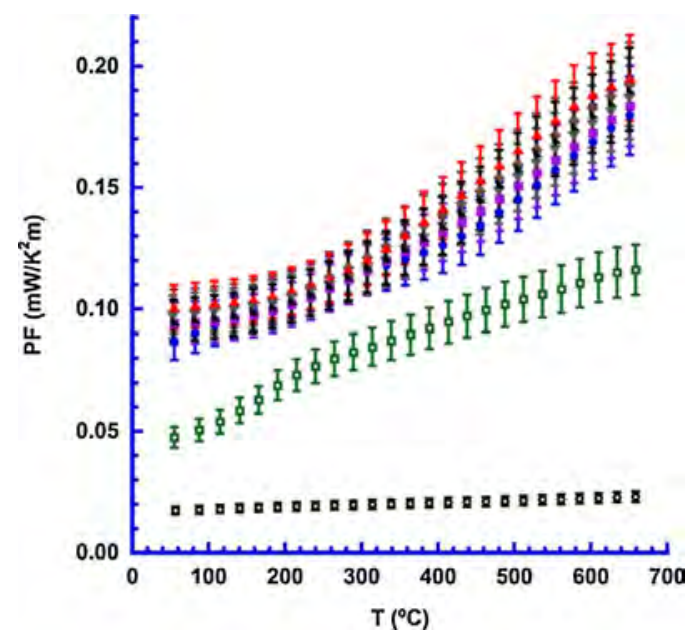

Fig. 5. Temperature dependence of power factor for $\mathrm{Bi}_{2} \mathrm{Sr}_{2-\mathrm{x}} \mathrm{Na}_{\mathrm{x}} \mathrm{Co}_{2} \mathrm{O}_{\mathrm{y}}$ as-grown samples with x: 0 0; and 0.075; and annealed ones with x: 0; 0.025; 0.05; $\Delta$ 0.075; $\nabla$ 0.10 ; and 0.125 . The bars illustrate the uncertainty of the measured values.

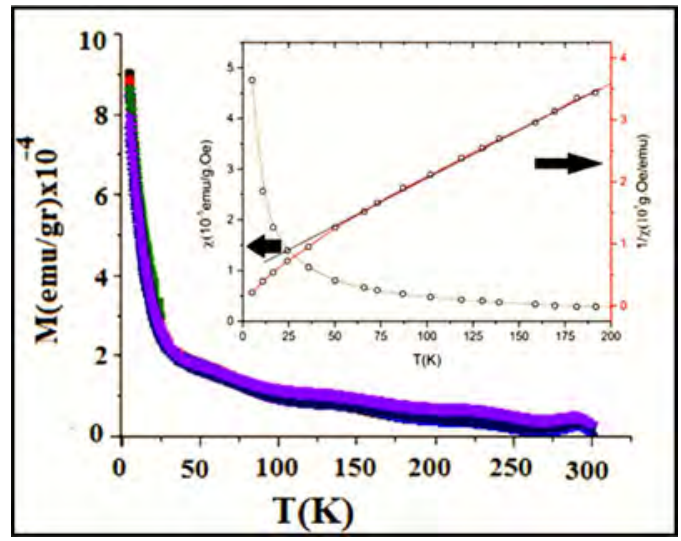

Fig. 6. DC-magnetization curves of all samples measured at 20 Oe external applied field. The inset presents the DC-magnetic susceptibility and inverse DC-magnetic susceptibility curves for annealed undoped samples also measured under 20 Oe external applied field.

In the high temperature region, the curves exhibit a typical Curie-Weiss behavior, described by the Curie-Weiss law formula:

$\frac{1}{\chi_{D C}}=\frac{H}{M}=\frac{T-\theta}{C}$

where $\theta$ and $C$ are the Curie-Weiss temperature and Curie constant, respectively. According to this law, the high temperature region of the curves should be fitted to a straight line when plotting the inverse susceptibility $(1 / \chi)$ versus $T$, as shown in the inset of Fig. 6 . Taking into account that all the results are very similar, only the ones for the undoped samples are displayed. The Curie constant, estimated from the curve slope, is $7.2 \times 10^{-4} \mathrm{emu} \mathrm{K} / \mathrm{g}$. In addition, from the $1 / \chi \rightarrow 0$ extrapolations in the high- $T$ part of the curve, negative paramagnetic Curie temperature $(-48.6 \mathrm{~K})$ has been obtained. This behavior clearly indicates that the paramagnetic regime at high temperature is dominated by antiferromagnetic fluctuations. However, the $\chi(T)$ curves do not exhibit a clear transition attributable to a long-range antiferromagnetic state.

The effective magnetic moment for each compound, $\mu_{\text {eff }}$, has been calculated using the following equation:

$\mu_{e f f}=\left[\frac{3 k_{B} C M_{w}}{N}\right]^{1 / 2}$

where, $k_{B}, C, M_{w}$, and $N$ are the Boltzmann constant $\left(1.38 \times 10^{-16} \mathrm{erg} /\right.$ $\mathrm{K}$ ), Curie constant, the compound molecular weight, and Avogadro number $\left(6.02 \times 10^{23}\right.$ atoms $\left./ \mathrm{mol}\right)$, respectively. It has been determined that $\mu_{\text {eff }}$ was approximately the same $\left(\approx 2 \mu_{B}\right)$ for all samples, without any Na-substitutional effect.

Magnetic hysteresis cycles, as a function of the external applied field, determined in the 0.15 Na-doped annealed samples at three different temperatures, are displayed in Fig. 7. As it can be observed in the graph, no hysteresis cycle is produced, indicating a paramagnetic behavior at temperatures higher than $15 \mathrm{~K}$, without any magnetic phase transition. Moreover, the slope of the curves decreases when the temperature increases indicating a reduction of magnetization, due to an easier orientation of magnetic moments at high temperatures.

All these results demonstrate that Na-doping of LFZ textured materials, followed by an adequate annealing are very useful to raise the thermoelectric performances of $\mathrm{Bi}_{2} \mathrm{Sr}_{2} \mathrm{Co}_{2} \mathrm{O}_{\mathrm{y}}$ materials. On the other hand, these modifications have no effect on the magnetic properties, due to the non-magnetic nature of $\mathrm{Na}$ cation.

\section{Conclusions}

Na-doped $\mathrm{Bi}_{2} \mathrm{Sr}_{2} \mathrm{Co}_{2} \mathrm{O}_{\mathrm{x}}$ ceramic materials have been prepared by the solid-state route, and textured through the laser floating zone 


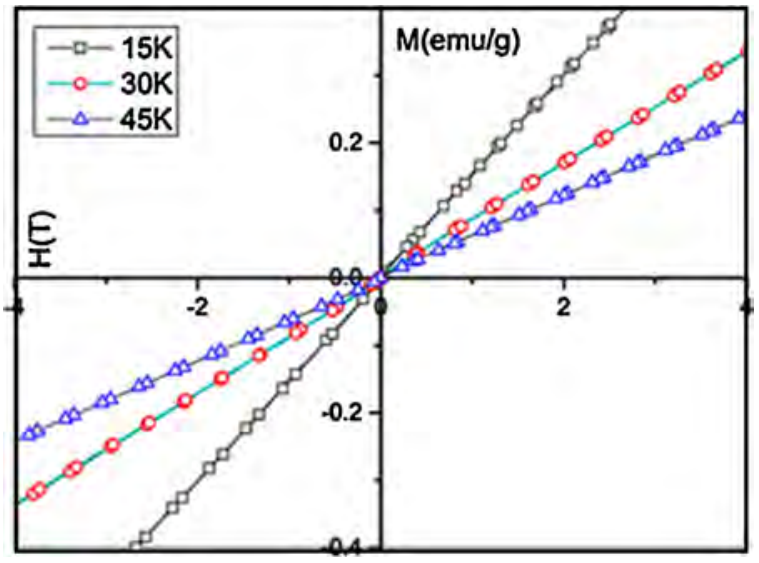

Fig. 7. Hysteresis curves for 0.15 Na-doped annealed samples measured at 15, 30, and $45 \mathrm{~K}$.

technique. As-grown samples are composed by the thermoelectric phase, accompanied by a relatively large amount of secondary phases due to the incongruent melting of this compound. After annealing, the amount and number of secondary phases are drastically reduced. Moreover, Na-doping has further increased the thermoelectric phase content and improved grain orientation. These microstructural modifications are reflected in a drastic decrease of electrical resistivity after the thermal treatment. Seebeck coefficient has also been raised in annealed samples. As a consequence, PF values determined in these samples are more than twice the measured in as-grown ones. Furthermore, they are much higher than the best ones reported in the literature in hot-forged materials. From the magnetic point of view, all samples are very similar, their magnetic susceptibility values sharply drop between 5 and $35 \mathrm{~K}$, slowly decreasing at higher temperatures. The paramagnetic Curie temperature $(-48.6 \mathrm{~K})$ indicates that antiferromagnetic fluctuations are dominant in the high- $T$ part of the paramagnetic regime. The effective magnetic moment $\left(\approx 2 \mu_{B}\right)$ was approximately the same for all annealed samples. On the other hand, no hysteresis cycles are observed in the $M-H$ measurements.

All these results show that the thermoelectric performances of $\mathrm{Bi}_{2} \mathrm{Sr}_{2} \mathrm{Co}_{2} \mathrm{O}_{\mathrm{y}}$ ceramics can be tuned up by adequate doping, texturing, and annealing, leading to promising thermoelectric materials for practical applications.

\section{Acknowledgements}

This work is supported by Research Fund of Çukurova University, Adana, Turkey, under grant contracts no: FDK-2016-6105. The authors wish to thank the MINECO-FEDER (Project MAT2013-46505-C3-1-R), Universidad de Zaragoza (Project UZ2017-TEC-03), and the Gobierno de Aragón-FEDER (Research Groups T12 and T87) for financial support. Authors acknowledge the use of Servicio General de Apoyo a la Investigación-SAI, Universidad de Zaragoza.

\section{References}

[1] G. Mahan, B. Sales, J. Sharp, Thermoelectric materials: new approaches to an old problem, Phys. Today 50 (1997) 42-47.

[2] L.E. Bell, Cooling, heating, generating power, and recovering waste heat with thermoelectric systems, Science 321 (2008) 1457-1461.

[3] H. Naito, Y. Kohsaka, D. Cooke, H. Arashi, Development of a solar receiver for a high-efficiency thermoionic/thermoelectric conversion system, Sol. Energy 58 (1996) 191-195.

[4] C.M. Kim, Y.J. Hwang, Y.H. Ryu, US Patent US6393842. May, (2002).

[5] M.H. Elsheikh, D.A. Shnawah, M.F.M. Sabri, S.B.M. Said, M.H. Hassan, M.B.A. Bashir, M. Mohamad, A review on thermoelectric renewable energy: principle parameters that affect their performance, Renew. Sust. Energy Rev. 30 (2014) 337-355.

[6] D.M. Rowe, Thermoelectrics Handbook: Macro to Nano, 1st ed., CRC Press, Boca Raton, FL, 2006.
[7] J.M. Santamaria, J. Alkorta, J.G. Sevillano, Mechanical properties of bismuth telluride $\left(\mathrm{Bi}_{2} \mathrm{Te}_{3}\right)$ processed by high pressure torsion (HPT), Bol. Soc. Esp. Ceram. V 52 (2013) 137-142.

[8] H.C. Wang, J.-H. Bahk, C. Kang, J. Hwang, K. Kim, J. Kim, P. Burke, J.E. Bowers, A.C. Gossard, A. Shakouri, W. Kim, Right sizes of nano- and microstructures for high-performance and rigid bulk thermoelectrics, Proc. Natl. Acad. Sci. U. S. A. 111 (2014) 10949-10954.

[9] H.C. Wang, J. Hwang, M.L. Snedaker, I.-H. Kim, C. Kang, J. Kim, G.D. Stucky, J. Bowers, W. Kim, High thermoelectric performance of a heterogeneous PbTe nanocomposite, Chem. Mater. 27 (2015) 944-949.

[10] I. Terasaki, Y. Sasago, K. Uchinokura, Large thermoelectric power in $\mathrm{NaCo}_{2} \mathrm{O}_{4}$ single crystals, Phys. Rev. B 56 (1997) 12685-12687.

[11] M. Abdellahi, M. Bahmanpour, M. Bahmanpour, Modeling seebeck coefficient of $\mathrm{Ca}_{3-\mathrm{x}} \mathrm{M}_{\mathrm{x}} \mathrm{Co}_{4} \mathrm{O}_{9}(\mathrm{M}=\mathrm{Sr}, \mathrm{Pr}, \mathrm{Ga}, \mathrm{Ca}, \mathrm{Ba}, \mathrm{La}, \mathrm{Ag})$ thermoelectric ceramics, Ceram. Int 41 (2015) 345-352.

[12] F. Li, J.F. Li, J.H. Li, F.Z. Yao, The effect of Cu substitution on microstructure and thermoelectric properties of $\mathrm{LaCoO}_{3}$ ceramics, Phys. Chem. Phys. 14 (2012) 12213-12220.

[13] K. Rubesova, T. Hlasek, V. Jakes, S. Huber, J. Hejtmanek, D. Sedmidubsky, Effect of a powder compaction process on the thermoelectric properties of $\mathrm{Bi}_{2} \mathrm{Sr}_{2} \mathrm{Co}_{1.8} \mathrm{O}_{\mathrm{x}}$ ceramics, J. Eur. Ceram. Soc. 35 (2015) 525-531.

[14] G. Constantinescu, M.A. Rasekh Sh Torres, M.A. Madre, J.C. Diez, A. Sotelo, Enhancement of the high-temperature thermoelectric performance of $\mathrm{Bi}_{2} \mathrm{Ba}_{2} \mathrm{Co}_{2} \mathrm{O}_{\mathrm{x}}$ ceramics, Scr. Mater. 68 (2013) 75-78.

[15] A. Sotelo, M.A. Torres, Sh. Rasekh, M.A. Madre, J.C. Diez, Effect of precursors on the microstructure and electrical properties of $\mathrm{Bi}_{2} \mathrm{Ba}_{2} \mathrm{Co}_{2} \mathrm{O}_{x}$, J. Aust. Ceram. Soc. (2017), http://dx.doi.org/10.1007/s41779-017-0070-6.

[16] H. Wang, C.L. Wang, Thermoelectric properties of $\mathrm{Yb}$-doped $\mathrm{La}_{0.1} \mathrm{Sr}_{0.9} \mathrm{TiO}_{3}$ ceramics at high temperature, Ceram. Int. 39 (2013) 941-946.

[17] Y.H. Zhu, W.B. Su, J. Liu, Y.C. Zhou, J. Li, X. Zhang, Y. Du, C.L. Wang, Effects of Dy and $\mathrm{Yb}$ co-doping on thermoelectric properties of $\mathrm{CaMnO}_{3}$ ceramics, Ceram. Int. 41 (2015) 1535-1539.

[18] Y. Miyazaki, Crystal structure and thermoelectric properties of the misfit-layered cobalt oxides, Solid State Ionics 172 (2004) 463-467.

[19] H. Leligny, D. Grebille, O. Perez, A.C. Masset, M. Hervieu, B. Raveau, A five-dimensional structural investigation of the misfit layer compound $\left[\mathrm{Bi}_{0.87} \mathrm{SrO}_{2}\right]_{2}\left[\mathrm{CoO}_{2}\right]_{1.82}$, Acta Cryst. B 56 (2000) 173-182.

[20] A. Maignan, D. Pelloquin, S. Hebert, Y. Klein, M. Hervieu, Thermoelectric power in misfit cobaltites ceramics: optimization by chemical substitutions, Bol. Soc. Esp. Ceram. V 45 (2006) 122-125.

[21] G. Constantinescu, M.A. Rasekh Sh Torres, J.C. Diez, M.A. Madre, A. Sotelo, Effect of $\mathrm{Sr}$ substitution for $\mathrm{Ca}$ on the $\mathrm{Ca}_{3} \mathrm{Co}_{4} \mathrm{O}_{9}$ thermoelectric properties, J. Alloys Compd. 577 (2013) 511-515.

[22] S. Butt, Y.-C. Liu, J.-L. Lan, K. Shehzad, B. Zhan, Y. Lin, C.-W. Nan, High-temperature thermoelectric properties of La and Fe co-doped Ca-Co-O misfit-layered cobaltites consolidated by spark plasma sintering, J. Alloys Compd. 588 (2014) $277-283$.

[23] H.S. Hao, Q.L. He, L.M. Zhao, Thermoelectric properties of Cu-substituted $\mathrm{Bi}_{2} \mathrm{Ca}_{2} \mathrm{Co}_{2} \mathrm{O}_{y}$ misfit oxides, Adv. Mater. Res. 284-286 (2011) 2263-2267.

[24] N. Prasoetsopha, S. Pinitsoontorn, T. Kamwanna, V. Amornkitbamrung, K. Kurosaki, Y. Ohishi, H. Muta, S. Yamanaka, The effect of $\mathrm{Cr}$ substitution on the structure and properties of misfit-layered $\mathrm{Ca}_{3} \mathrm{Co}_{4-\mathrm{x}} \mathrm{Cr}_{\mathrm{x}} \mathrm{O}_{9+\delta}$ thermoelectric oxides, $\mathrm{J}$. Alloys Compd. 588 (2014) 199-205.

[25] F. Kahraman, M.A. Madre, C. Rasekh Sh Salvador, P. Bosque, M.A. Torres, J.C. Diez, A. Sotelo, Enhancement of mechanical and thermoelectric properties of $\mathrm{Ca}_{3} \mathrm{Co}_{4} \mathrm{O}_{9}$ by Ag addition, J. Eur. Ceram. Soc. 35 (2015) 3835-3841.

[26] H. Itahara, C. Xia, J. Sugiyama, T. Tani, Fabrication of textured thermoelectric layered cobaltites with various rock salt-type layers by using $\beta-\mathrm{Co}(\mathrm{OH})_{2}$ platelets as reactive templates, J. Mater. Chem. 14 (2004) 61-66.

[27] N.Y. Wu, T.C. Holgate, N.V. Nong, N. Pryds, S. Linderoth, High temperature thermoelectric properties of $\mathrm{Ca}_{3} \mathrm{Co}_{4} \mathrm{O}_{9+\delta}$ by auto-combustion synthesis and spark plasma sintering, J. Eur. Ceram. Soc. 34 (2014) 925-931.

[28] H. Wang, X. Sun, X. Yan, D. Huo, X. Li, J.-G. Li, X. Ding, Fabrication and thermoelectric properties of highly textured $\mathrm{Ca}_{9} \mathrm{Co}_{12} \mathrm{O}_{28}$ ceramic, J. Alloys Compd. 582 (2014) 294-298.

[29] G. Rasekh Sh Constantinescu, M.A. Torres, M.A. Madre, J.C. Diez, A. Sotelo, Growth rate effect on microstructure and thermoelectric properties of melt grown $\mathrm{Bi}_{2} \mathrm{Ba}_{2} \mathrm{Co}_{2} \mathrm{O}_{\mathrm{x}}$ textured ceramics, Adv. Appl. Ceram. 111 (2012) 490-494.

[30] N.M. Ferreira, F.M. Rasekh Sh Costa, M.A. Madre, A. Sotelo, J.C. Diez, M.A. Torres, New method to improve the grain alignment and performance of thermoelectric ceramics, Mater. Lett. 83 (2012) 144-147.

[31] A. Sotelo, M.A. Rasekh Sh Torres, P. Bosque, M.A. Madre, J.C. Diez, Improved thermoelectric performances in textured $\mathrm{Bi}_{1.6} \mathrm{~Pb}_{0.4} \mathrm{Ba}_{2} \mathrm{Co}_{2} \mathrm{O}_{\mathrm{y}} / \mathrm{Ag}$ composites, Ceram. Int. 42 (2016) 18592-18596.

[32] A. Sotelo, G. Rasekh Sh Constantinescu, M.A. Torres, M.A. Madre, J.C. Diez, Improvement of textured $\mathrm{Bi}_{1.6} \mathrm{~Pb}_{0.4} \mathrm{Sr}_{2} \mathrm{Co}_{1.8} \mathrm{O}_{\mathrm{x}}$ thermoelectric performances by metallic Ag additions, Ceram. Int. 39 (2013) 1597-1602.

[33] F.M. Rasekh Sh Costa, N.M. Ferreira, M.A. Torres, M.A. Madre, J.C. Diez, A. Sotelo, Use of laser technology to produce high thermoelectric performances in $\mathrm{Bi}_{2} \mathrm{Sr}_{2} \mathrm{Co}_{1.8} \mathrm{O}_{\mathrm{x}}$, Mater. Des. 75 (2015) 143-148.

[34] E. Combe, R. Funahashi, T. Barbier, F. Azough, R. Freer, Decreased thermal conductivity in $\mathrm{Bi}_{2} \mathrm{Sr}_{2} \mathrm{Co}_{2} \mathrm{O}_{\mathrm{x}}$ bulk materials prepared by partial melting, J. Mater. Res. 31 (2016) 1296-1305.

[35] A. Sotelo, M.A. Torres, G. Constantinescu, J.C. Rasekh Sh Diez, M.A. Madre, Effect of $\mathrm{Ag}$ addition on the mechanical and thermoelectric performances of annealed $\mathrm{Bi}_{2} \mathrm{Sr}_{2} \mathrm{Co}_{1.8} \mathrm{O}_{\mathrm{x}}$ textured ceramics, J. Eur. Ceram. Soc. 32 (2012) 3745-3751. 
[36] D. Mercurio, J.C. Champarnaud-Mesjard, B. Frit, P. Conflant, J.C. Boivin, T. Vogt, Thermal evolution of the crystal-structure of the rhombohedral $\mathrm{Bi}_{0.75} \mathrm{Sr}_{0.25} \mathrm{O}_{1.375}$ phase-a single-crystal neutron-diffraction study, J. Solid State Chem. 112 (1994) 1-8.

[37] D. Pelloquin, A.C. Masset, A. Maignan, C. Michel, M. Hervieu, B. Raveau, A new cobaltite with a tubular structure: $\mathrm{bi}_{3.7} \mathrm{Sr}_{11.4} \mathrm{Co}_{8} \mathrm{O}_{28-\mathrm{d}}$, the $\mathrm{n}=2$ member of the series $\left(\mathrm{Bi}_{2} \mathrm{Sr}_{2} \mathrm{CoO}_{6}\right)_{\mathrm{n}}\left(\mathrm{Sr}_{8} \mathrm{Co}_{6} \mathrm{O}_{16-\mathrm{d}}\right)$, Chem. Mater. 11 (1999) 84-89.

[38] R.J. Makkonen, Crystallographic and magnetic properties of solid solutions of $\mathrm{CoCo}_{2} \mathrm{O}_{4}$ and $\mathrm{CoCr}_{2} \mathrm{O}_{4}$, Suomen Kemistilehti A 35 (1962) 230-234.

[39] M.A. Madre, J.C. Rasekh Sh Diez, A. Sotelo, New solution method to produce high performance thermoelectric ceramics: a case study of Bi-Sr-Co-O, Mater. Lett. 64 (2010) 2566-2568.

[40] F.M. Costa, N.M. Ferreira, A.J.S. Rasekh Sh Fernandes, M.A. Torres, M.A. Madre, J.C. Diez, A. Sotelo, Very large superconducting currents induced by growth tailoring, Crystal Growth Des. 15 (2015) 2094-2101.

[41] N.M. Ferreira, A.V. Kovalevsky, M.C. Ferro, F.M. Costa, J.R. Frade, A new concept of ceramic consumable anode for iron pyroelectrolysis in magnesium aluminosilicate melts, Ceram. Int. 42 (2016) 11070-11076.

[42] A. Rasekh Sh Sotelo, M.A. Torres, P. Bosque, M.A. Madre, J.C. Diez, Thermoelectric properties of directionally grown $\mathrm{Bi}_{2} \mathrm{Ba}_{2} \mathrm{Co}_{2} \mathrm{O} / \mathrm{Ag}$ composites: effect of annealing, J. Mater. Sci. Mater. Electron. 27 (2016) 12964-12973.

[43] M.A. Madre, F.M. Costa, N.M. Ferreira, S.I.R. Costa, M.A. Rasekh Sh Torres, J.C. Diez, V.S. Amaral, J.S. Amaral, A. Sotelo, High thermoelectric performance in $\mathrm{Bi}_{2-\mathrm{x}} \mathrm{Pb}_{\mathrm{x}} \mathrm{Ba}_{2} \mathrm{Co}_{2} \mathrm{O}_{\mathrm{y}}$ promoted by directional growth and annealing, J. Eur. Ceram. Soc. 36 (2016) 67-74.

[44] A. Sotelo, F.M. Costa, N.M. Ferreira, A. Kovalevsky, M.C. Ferro, V.S. Amaral, J.S. Amaral, Sh. Rasekh, M.A. Torres, M.A. Madre, J.C. Diez, Tailoring $\mathrm{Ca}_{3} \mathrm{Co}_{4} \mathrm{O}_{9}$ microstructure and performances using a transient liquid phase sintering additive, J. Eur. Ceram. Soc. 36 (2016) 1025-1032.

[45] T. Itoh, I. Terasaki, Thermoelectric properties of $\mathrm{Bi}_{2.3-\mathrm{x}} \mathrm{Pb}_{\mathrm{x}} \mathrm{Sr}_{2.6} \mathrm{Co}_{2} \mathrm{O}_{\mathrm{y}}$ single crystals, Jpn. J. Appl. Phys. 39 (2000) 6658-6660.

[46] W. Shin, N. Murayama, Thermoelectric properties of (Bi,Pb)-Sr-Co-O oxide, J. Mater. Res. 15 (2000) 382-386. 